\title{
Helcococcus sueciensis sp. nov., isolated from a human wound
}

Correspondence

Paul A. Lawson

p.a.lawson@reading.ac.uk

\author{
Matthew D. Collins, ${ }^{1}$ Enevold Falsen, ${ }^{2}$ Kit Brownlee ${ }^{1}$ and Paul A. Lawson ${ }^{1}$ \\ 'School of Food Biosciences, University of Reading, Reading RG6 6AP, UK \\ ${ }^{2}$ Culture Collection, Department of Clinical Bacteriology, University of Göteborg, SE-413 46 \\ Göteborg, Sweden
}

The genus Helcococcus was described by Collins et al. (1993) to accommodate some Gram-positive, catalase-negative, coccoid organisms from human clinical sources. Originally, the genus was monospecific, containing only the species Helcococcus kunzii (Collins et al., 1993). H. kunzii has been isolated in mixed culture from human wounds and breast masses (Caliendo et al., 1995) and has been reported as the sole isolate from an infected sebaceous cyst (Peel et al., 1997). Recently, a second species, Helcococcus ovis, which was recovered during a post-mortem examination of a sheep and from milk of a sheep with subclinical mastitis, has been assigned to the genus (Collins et al., 1999). Phylogenetically, $H$. kunzii and $H$. ovis are members of the Clostridium subphylum, where they form a distinct and robust group that is related to, but distinct from, a number of genera that encompass species formerly assigned to the genus Peptostreptococcus (e.g. Anaerococcus, Finegoldia, Gallicola and Peptoniphilus). During the course of a study of taxonomically problematic, Gram-positive, catalase-negative cocci from human clinical specimens, we have characterized a Helcococcus-like organism that does not appear to correspond to any recognized species of this genus. On the basis of the results of a polyphasic taxonomic study, we describe a third species of the genus Helcococcus, Helcococcus sueciensis sp. nov.

Published online ahead of print on 27 February 2004 as DOI 10.1099/ ijs.0.63077-0.

The GenBank/EMBL/DDBJ accession number for the 16S rRNA gene sequence of strain CCUG $47334^{\top}$ is AJ579914.
Bacterial isolate CCUG $47334^{\mathrm{T}}$ was isolated from a wound of an 83-year-old woman from Sweden; it was referred to the Culture Collection of the University of Göteborg, Sweden, for identification. No other clinical information is known. For biochemical testing, the strain was cultured on Columbia agar (Difco) supplemented with $5 \%$ (v/v) horse blood at $37^{\circ} \mathrm{C}$ and incubated anaerobically. The strain was characterized biochemically by using a combination of conventional tests, as described in the Virginia Polytechnic Institute Anaerobe Laboratory Manual (Holdeman et al., 1977), and commercially available API Rapid ID 32 Strep and API Rapid ID 32A systems according to the manufacturer's instructions (bioMérieux). PAGE analysis of whole-cell proteins was performed as described by Pot et al. (1994). For densitometric analysis and normalization and interpretation of protein patterns, the GCW 3.0 software package (Applied Maths) was used. Similarity between all pairs of traces was expressed by using the Pearson product-moment correlation coefficient converted, for convenience, to a percentage similarity. The $\mathrm{G}+\mathrm{C}$ content $(\mathrm{mol} \%)$ of the DNA of the isolate was determined by HPLC according to Mesbah et al. (1989). For phylogenetic analysis, the 16S rRNA gene of the strain was amplified by PCR and sequenced directly by using a Taq DyeDeoxy terminator cycle sequencing kit (Applied Biosystems) and an automatic DNA sequencer (model 373A; Applied Biosystems). The closest known relatives of the new isolate were determined by performing GenBank/EMBL database searches. These sequences and those of other known related strains were retrieved from GenBank/EMBL and aligned with the newly determined sequence by using 
the program DNATools (Rasmussen, 1995). In the resulting multiple sequence alignment, approximately 100 bases at the $5^{\prime}$ end of the rRNA were omitted from further analysis, because of alignment uncertainties due to the highly variable region V1, by using the program GeneDoc (Nicholas et al., 1997). A phylogenetic tree was reconstructed according to the neighbour-joining method with the programs DNATools and TREEVIEW (Page, 1996) and the stability of the groupings was estimated by bootstrap analysis (1000 replications) by using the same programs.

The unidentified organism consisted of Gram-positive, coccus-shaped cells that formed pairs or short chains. Cells were non-acid-fast, non-spore-forming and non-motile. The organism was catalase-negative and facultatively anaerobic, but grew best under anaerobic conditions. Pinpoint, grey, non-haemolytic colonies were formed after $48 \mathrm{~h}$ anaerobic incubation on fastidious anaerobe agar with $5 \%$ $(\mathrm{v} / \mathrm{v})$ horse blood. The strain was unidentified by using commercial API biochemical kits. By using conventional methods, it was found that the strain formed acid from glucose, lactose, maltose, mannose (weakly), sorbitol and starch (weakly). It failed to produce acid from cellobiose, sucrose and xylose. The isolate was indole-negative and did not reduce nitrate. By using the API Rapid 32 Strep system, it was found that the organism formed acid from maltose, lactose and trehalose and gave positive reactions for alkaline phosphatase, $N$-acetyl- $\beta$-glucosaminidase and $\beta$-galactosidase. All other tests in this gallery gave negative reactions, producing a numerical code of 44034201000 . By using the API Rapid ID $32 \mathrm{~A}$ system, positive reactions were obtained for alkaline phosphatase, alanine arylamidase, arginine arylamidase, $\beta$-galactosidase, glycine arylamidase, glutamyl glutamic acid arylamidase, histidine arylamidase, leucine arylamidase, $\mathrm{N}$ acetyl- $\beta$-glucosaminidase, phenylalanine arylamidase, serine arylamidase and tyrosine arylamidase. All other tests gave negative results, producing an API Rapid ID 32A numerical profile of 0101413707.

Cellular morphology and general physiological and biochemical reactions of the organism were consistent with its tentative assignment to the genus Helcococcus, but it did not appear to correspond to either of the two currently recognized members of this genus, i.e. H. kunzii or $H$. ovis. Determination of a DNA G + C content of $29.5 \mathrm{~mol} \%$ was consistent with this provisional assignment. To investigate the possible association of the unknown bacterium with Helcococcus species, its whole-cell protein profile was compared with those of H. kunzii, H. ovis and some related organisms. Comparative analysis of whole-cell protein profiles showed that the unknown organism was distinct from all currently defined species of the genus Helcococcus and related Gram-positive cocci (data not shown). A dendrogram based on a subset of species and depicting a comparative protein analysis of the unidentified species and its closest relatives is shown in Fig. 1. The unknown organism formed a relatively long line, joining the $\mathrm{H}$. kunzii cluster at a similarity value of $<55 \%$. The next most closely related species were Peptostreptococcus micros and H. ovis, joining at $<50 \%$ (Fig. 1). To determine the phylogenetic relationships of the unidentified organism, its almostcomplete 16S rRNA gene sequence $(>1400 \mathrm{nt})$ was determined. Sequence database searches confirmed that the unknown isolate was related most closely to species of the genus Helcococcus. Highest sequence similarity values were shown with $H$. ovis $(94 \cdot 2 \%$ similarity) and $H$. kunzii ( $92.6 \%$ similarity); species of other related genera (e.g. Anaerococcus, Finegoldia and Peptostreptococcus) were related much more distantly ( $<90 \%$; data not shown). Treeing analysis further demonstrated the affinity of the unidentified bacterium with the genus Helcococcus, as the novel bacterium formed a distinct subline that branched at the base of the genus (Fig. 2).

On the basis of both phenotypic and molecular phylogenetic studies, it is clear that the unidentified Gram-positive, catalase-negative, coccus-shaped organism that was recovered from a human wound represents a novel member of the genus Helcococcus. Phylogenetically, the unknown bacterium formed a robust cluster with the genus Helcococcus, supported by a bootstrap resampling value of $100 \%$.

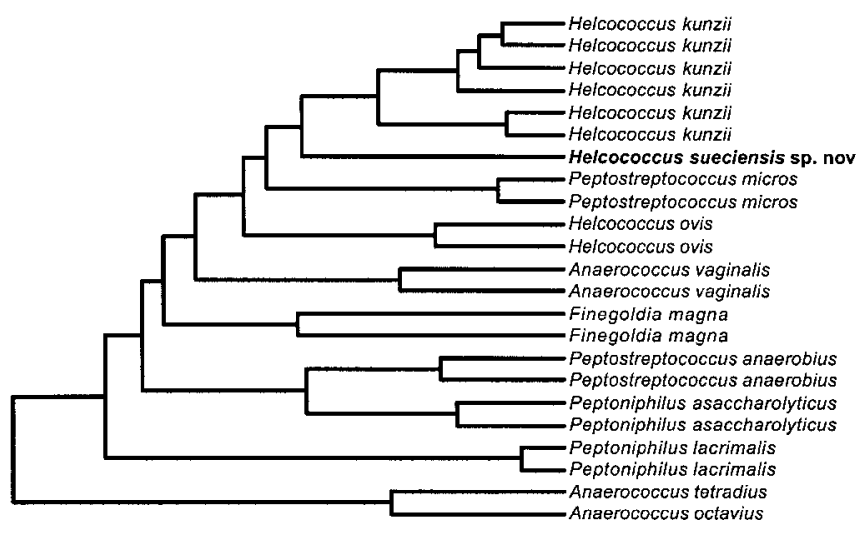

Fig. 1. Similarity dendrogram based on whole-cell protein patterns of Helcococcus sueciensis sp. nov. and some related species. Levels of correlation are expressed as percentages of similarity for convenience. 


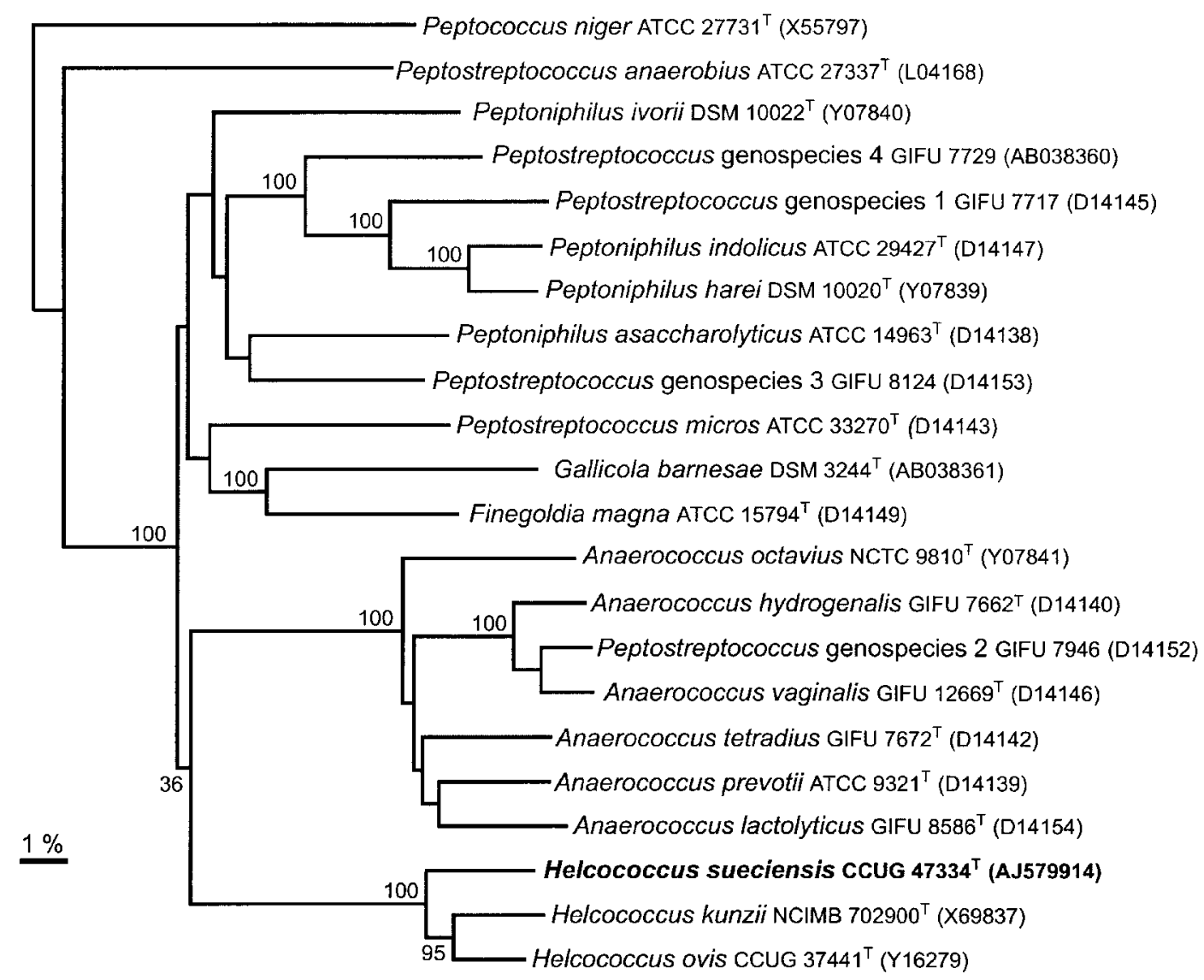

Fig. 2. Unrooted tree showing the phylogenetic relationships of Helcococcus sueciensis sp. nov. The tree, constructed by using the neighbour-joining method, was based on a comparison of approximately $1327 \mathrm{nt}$. Bootstrap values, each expressed as a percentage of 500 replications, are given at branching points. Bar, $1 \%$ sequence divergence.

Sequence divergence values of approximately 5-7\% reinforced the separateness of the unidentified coccus with respect to recognized helcococcal species. Although there is no precise correlation between 16S rRNA gene sequence divergence values and species delineation, it is now generally accepted that organisms that display values of $3 \%$ or more do not belong to the same species. The observed $>5 \%$ sequence divergence between the unidentified clinical isolate and $H$. kunzii and $H$. ovis is therefore consistent with separate species status. Strong support for the separateness of the unknown bacterium also comes from phenotypic evidence. In particular, comparative whole-cell protein profiling shows that the unidentified organism is distinct from the aforementioned Helcococcus species. Furthermore, the unknown bacterium is biochemically distinct and can be distinguished readily from the two currently defined Helcococcus species. Therefore, based on the distinct phenotypic characteristics of the unidentified coccus-shaped bacterium and molecular phylogenetic evidence, we consider that it warrants classification as a novel species of the genus Helcococcus, for which the name Helcococcus sueciensis sp. nov. is proposed. The novel species can be distinguished readily from other Helcococcus species by using the tests shown in Table 1. Although only a single strain of $H$. sueciensis is currently known, we consider that the formal description of this species, accompanied by $16 \mathrm{~S}$ rRNA gene sequence data and biochemical criteria to help with identification, will in future facilitate its recognition in the routine laboratory, thereby permitting the recovery of additional strains and an evaluation of its distribution, clinical prevalence and possible significance.

\section{Description of Helcococcus sueciensis sp. nov.}

Helcococcus sueciensis (su.e.ci.en'sis. N.L. masc. adj. sueciensis from Sweden, the country in which the organism was isolated).

Cells are Gram-positive and coccoid and occur singly, in pairs or in short chains. Cells are non-acid-fast, non-sporeforming and non-motile. Pinpoint, grey, non-haemolytic colonies form after $48 \mathrm{~h}$ anaerobic incubation on fastidious anaerobe agar with $5 \%(\mathrm{v} / \mathrm{v})$ horse blood. Catalase-negative and facultatively anaerobic, but grows best under anaerobic conditions. End products of glucose metabolism are acetic 
Table 1. API Rapid ID 32 Strep tests that are useful in distinguishing species of the genus Helcococcus

,$+>90 \%$ of isolates give positive reactions;,$-<10 \%$ of isolates give positive reactions; $\mathrm{v}$, variable.

\begin{tabular}{|lccc|}
\hline Characteristic & $\begin{array}{c}\text { H. sueciensis } \\
\text { sp. nov. }\end{array}$ & H. ovis & H. kunzii \\
\hline Acid from: & & & \\
$\quad$ Lactose & + & - & + \\
Pullulan & - & - & $\mathrm{V}$ \\
Trehalose & + & + & + \\
Production of: & & - & + \\
Alkaline phosphatase & + & + & - \\
$\beta$-Glucosidase & - & - & + \\
$\beta$-Glucuronidase & - & - & + \\
Pyroglutamic acid arylamidase & - & & \\
$N$-Acetyl- $\beta$-glucosaminidase & + & & \\
\end{tabular}

and lactic acids. In conventional tests, acid is produced from glucose, lactose, maltose, mannose (weakly), sorbitol and starch (weakly). Acid is not formed from cellobiose, sucrose or xylose. In commercial API systems, acid is produced from glucose, maltose, lactose and trehalose, but not from D-arabitol, L-arabinose, cyclodextrin, glycogen, mannitol, mannose, melibiose, melezitose, methyl $\beta$-Dglucopyranoside, pullulan, raffinose, D-ribose, sorbitol, sucrose or tagatose. Activity is detected for alkaline phosphatase, alanine arylamidase, arginine arylamidase, $\beta$-galactosidase, glycine arylamidase, glutamyl glutamic acid arylamidase, histidine arylamidase, leucine arylamidase, $N$-acetyl- $\beta$-glucosaminidase, phenylalanine arylamidase, serine arylamidase and tyrosine arylamidase. Activity is not detected for $\alpha$-arabinosidase, $\alpha$-fucosidase, $\alpha$-galactosidase, $\alpha$-glucosidase, $\beta$-glucosidase, $\beta$-galactosidase- 6 phosphate, glutamic acid decarboxylase, $\beta$-glucuronidase, glycyl tryptophan arylamidase, proline arylamidase, leucyl glycine arylamidase, $\beta$-mannosidase, pyroglutamic acid arylamidase or urease. Hippurate is not hydrolysed and indole is not produced. Nitrate is not reduced. VogesProskauer test is negative. $\mathrm{G}+\mathrm{C}$ content of the DNA is $29 \cdot 5 \mathrm{~mol} \%$.

The type strain is CCUG $47334^{\mathrm{T}}\left(=\mathrm{CIP} 108183^{\mathrm{T}}\right)$. Isolated from a human wound. Habitat unknown.

\section{Acknowledgements}

We appreciate the help of K. Molin, E. Inganäs and M. Ohlén in performing phenotypic analyses. We are also grateful to $\mathrm{H}$. Trüper for advice on the species name.

\section{References}

Caliendo, A. M., Jordan, C. D. \& Ruoff, K. L. (1995). Helcococcus, a new genus of catalase-negative, gram-positive cocci isolated from clinical specimens. J Clin Microbiol 33, 1638-1639.

Collins, M. D., Facklam, R. R., Rodrigues, U. M. \& Ruoff, K. L. (1993). Phylogenetic analysis of some Aerococcus-like organisms from clinical sources: description of Helcococcus kunzii gen. nov., sp. nov. Int J Syst Bacteriol 43, 425-429.

Collins, M. D., Falsen, E., Foster, G., Monasterio, L. R., Dominguez, L. \& Fernandez-Garazabal, J. F. (1999). Helcococcus ovis sp. nov., a Gram-positive organism from sheep. Int $J$ Syst Bacteriol 49, 1429-1432.

Holdeman, L. V., Cato, E. P. \& Moore, W. E. C. (editors) (1977). Anaerobe Laboratory Manual, 4th edn. Blacksburg, VA: Virginia Polytechnic Institute and State University.

Mesbah, M., Premachandran, U. \& Whitman, W. B. (1989). Precise measurement of the $\mathrm{G}+\mathrm{C}$ content of deoxyribonucleic acid by high-performance liquid chromatography. Int J Syst Bacteriol 39, 159-167.

Nicholas, K. B., Nicholas, H. B., Jr \& Deerfield, D. W., II (1997). GeneDoc: analysis and visualization of genetic variation. EMBNEW News 4, 14.

Page, R. D. M. (1996). TREEVIEW: an application to display phylogenetic trees on personal computers. Comput Appl Biosci 12, 357-358.

Peel, M. M., Davis, J. M., Griffin, K. J. \& Freedman, D. L. (1997). Helcococcus kunzii as sole isolate from an infected sebaceous cyst. J Clin Microbiol 35, 328-329.

Pot, B., Vandamme, P. \& Kersters, K. (1994). Analysis of electrophoretic whole-organism protein fingerprints. In Modern Microbial Methods. Chemical Methods in Prokaryotic Systematics, pp. 493-521. Edited by M. Goodfellow \& A. G. O’Donnell. Chichester: Wiley.

Rasmussen, S. W. (1995). DNATools, a software package for DNA sequence analysis. Carlsberg Laboratory, Copenhagen. 